\title{
Is an endothelial nitric oxide synthase gene mutation a risk factor in the origin of intraventricular hemorrhage?
}

\author{
Prasad Vannemreddy, M.D., ${ }^{1}$ Christina Notarianni, M.D., ${ }^{1}$ Krishna Yanamandra, Ph.D., 2 \\ DAWn NAPPER, B.S., ${ }^{2}$ AND JoSePH BOCChINI JR, M.D. ${ }^{2}$ \\ Departments of ${ }^{I}$ Neurosurgery and ${ }^{2}$ Pediatrics, Louisiana State University Health Sciences Center- \\ Shreveport, Louisiana
}

Object. Studies have shown decreased levels of nitric oxide (NO), the product of endothelial NO synthase (eNOS) gene activity, in infants with respiratory conditions and intraventricular hemorrhage (IVH). The authors evaluated the association of the $e N O S$ gene promoter polymorphism T-786C with the cause of these conditions (respiratory conditions and IVH) in premature infants.

Methods. Blood samples from 124 African American premature infants were studied. The DNA was isolated and microplate polymerase chain reaction-restriction fragment length polymorphism assay was performed. Genotypes were scored as: TT homozygotes with $140 \mathrm{bp}$ and $40 \mathrm{bp}$; CC homozygotes with $90 \mathrm{bp}, 50 \mathrm{bp}$, and $40 \mathrm{bp}$; and TC heterozygotes with $140 \mathrm{bp}, 90 \mathrm{bp}, 50 \mathrm{bp}$, and $40 \mathrm{bp}$. Genotypes were stratified according to ethnicity, preterm status, and prematurity conditions.

Results. The mutant allele $-786 \mathrm{C}$ was present in $15.3 \%$ of premature infants with respiratory distress syndrome, bronchopulmonary dysplasia, and IVH, compared with $7.25 \%$ in those premature infants without these conditions. A significant 2-fold increase of the mutant allele in patients compared with controls $(p=0.04$, OR 2.3) reveals that the eNOS $-786 \mathrm{C}$ allele could be a significant risk factor in the origin of respiratory conditions and IVH in premature infants.

Conclusions. These results suggest that the mutant eNOS $-786 \mathrm{C}$ allele is a significant risk factor in the origin of respiratory and IVH diseases, probably mediating an insufficient supply of endogenous NO in premature infants. (DOI: 10.3171/2009.10.FOCUSO9143)

$\begin{array}{llcl}\text { KEY WORDS } & \bullet & \text { hydrocephalus } \\ \text { prematurity } & \bullet & \text { endothelial nitric oxide synthase } & \text { intraventricular hemorrhage }\end{array}$

$\mathrm{N}$ ITRIC oxide is biosynthesized from L-arginine by the NOS enzyme. There are 3 forms of NOS: eNOS and neuronal NOS, both of which are constitutive forms, and the inducible form. Several single nucleotide polymorphisms in promoter and coding region exon 7 , as well as variable number of tandem repeats polymorphisms in intron4 of the eNOS gene have been reported. Mutant genotypes of these polymorphisms have been shown to reduce eNOS enzyme activity, resulting in reduced NO levels. Earlier studies have shown that NO is decreased in premature infants with persistent pulmonary hypertension. ${ }^{13}$ Our laboratory has previously shown an elevation of mutant endothelial genotypes in premature infants with respiratory distress..$^{23}$

\footnotetext{
Abbreviations used in this paper: $\mathrm{ACE}=$ angiotensin converting enzyme; $\mathrm{BPD}=$ bronchopulmonary dysplasia; $\mathrm{eNOS}=$ endothelial NOS; IL = interleukin; IVH = intraventricular hemorrhage; LSUHSC = Louisiana State University Health Sciences Center; $\mathrm{NO}=$ nitric oxide $; \mathrm{NOS}=\mathrm{NO}$ synthase PCR $=$ polymerase chain reaction; $\mathrm{RDS}=$ respiratory distress syndrome; RFLP $=$ restriction fragment length polymorphism; VLBW = very low birth weight.
}

Intraventricular hemorrhage is a condition of preterm neonates that occurs due to rupture of blood vessels within the germinal matrix tissue of the developing brain. The vessels of the germinal matrix are highly susceptible to rupture due to lack of surrounding adventitia in the capillary bed of these vessels and lack of autoregulation in this preterm structure of the brain. Furthermore, the effects of IVH can be devastating, including periventricular scarring, white matter gliosis, and free radical and cytokine generation, all of which produce secondary damage to the early developing brain. ${ }^{1-5,7}$ Studies have shown that infants who suffer large IVH are associated with an increased rate of developing major disabilities. As many as $60 \%$ of infants with Grade IV IVH will have severe motor and/or cognitive handicaps. ${ }^{6,18}$

Infants who suffer from this condition have been shown to be more likely to develop seizures and hydrocephalus than their gestational age-matched peers without IVH. Many of these infants will subsequently require CSF shunt placement, requiring lifelong maintenance. A previous study conducted by our institution (LSUHSCShreveport) found that pediatric shunts placed for post- 
hemorrhagic hydrocephalus had significantly shorter survival time when compared with shunts placed for other causes. This study prompted our institution to examine the etiopathology of IVH to further determine if any modifiable factors for this condition of prematurity were present.

Earlier studies have shown that respiratory conditions such as RDS, BPD, or hyaline membrane diseases are closely associated with IVH. ${ }^{11}$ Various genetic markers such as factor $\mathrm{V}$ Leiden, methylenetetrahydrofolate reductase, and prothrombin II gene polymorphisms have been found to be risk factors for IVH. ${ }^{20,21}$ Similarly, we have shown the relationship between several ILs and vascular gene markers with many conditions of prematurity in VLBW premature infants receiving ventilation therapy. ${ }^{20-22}$

In the present investigation, we studied the association of eNOS gene promoter polymorphism T-786C with the origin of respiratory and IVH conditions in premature African American infants. The rationale for the present study was that earlier studies from our laboratory have shown significant differences in the genotype frequencies in the eNOS gene. For example, the frequency of the $-786 \mathrm{C}$ mutant genotype in the promoter region of the eNOS gene was 2.5-fold higher in Caucasians compared with African Americans. The frequency of the 298Asp mutant genotype in exon 7 of the gene is 3-fold higher in Caucasians compared with that in African Americans. The frequency of variable number of tandem repeats $(27$ bp repeats) in intron 4 of the gene with 5 repeats (wildtype) is more common among African Americans than Caucasians. ${ }^{17}$ Thus, both cases and controls were studied within the African American patient population, and the majority of the patients delivered at our medical center were African Americans.

\section{Methods}

\section{Patient Population}

Approval to conduct this study was granted by the Institutional Review Board of the LSUHSC. Peripheral blood samples from 124 premature African American infants suffering from both IVH and respiratory conditions of prematurity were collected consecutively from the pediatric neonatal intensive care unit of LSUHSCShreveport. The respiratory conditions of prematurity included RDS and BPD. Data from a control group of 124 premature infants without either of these conditions were also collected consecutively. The DNA was subsequently isolated from both patient and control samples using Qiagen DNA isolation kits.

\section{Genotyping Assays}

The genotyping assay was modified from that used by Tsukada et al. ${ }^{16}$ to suit the large number of samples in our laboratory. Briefly, microplate PCR-RFLP assay was performed in $10 \mu \mathrm{l}$ with $1 \mu \mathrm{l}$ DNA, $3.25 \mathrm{mM} \mathrm{MgCl}_{2}$, $0.375 \mathrm{mM}$ deoxyribonucleoside triphosphate mix, $10 \times$ PCR reaction buffer II, 1 unit of Taq Gold polymerase (Applied Biosystems Corp.), and $0.015 \mu \mathrm{M}$ primer mix
TABLE 1: The frequency of eNOS T-786C genotypes in patients and controls

\begin{tabular}{lccccc}
\hline $\begin{array}{c}\text { Geno- } \\
\text { type }\end{array}$ & $\begin{array}{c}\text { No. of } \\
\text { Patients }\end{array}$ & $\begin{array}{c}\text { Fre- } \\
\text { quency }\end{array}$ & $\begin{array}{c}\text { No. of } \\
\text { Controls }\end{array}$ & $\begin{array}{c}\text { Fre- } \\
\text { quency }\end{array}$ & $\begin{array}{c}\text { p Value } \\
\text { (OR, 95\% Cl) }\end{array}$ \\
\hline -786TT & 43 & 0.69 & 53 & 0.86 & \\
-786TC & 19 & 0.31 & 9 & 0.15 & $0.03^{*}(2.6,1.1-6.2)$ \\
-786CC & 0 & 0 & 0 & 0 & \\
total & 62 & 1.0 & 62 & 1.0 & \\
\hline
\end{tabular}

* TC genotype frequency in patients was significantly different from controls.

with the following sequences: TGG AGA GTG CTG GTG TAC CCC A (forward), and GCC TCC ACC CCC ACC CTG TC (reverse).

The following PCR parameters were used: initial denaturation for 10 minutes at $94^{\circ} \mathrm{C}$, followed by 35 cycles of $94^{\circ} \mathrm{C}$ for 30 seconds, then $64^{\circ} \mathrm{C}$ for 30 seconds, and $72^{\circ} \mathrm{C}$ for 1 minute, with the last extension at $72^{\circ} \mathrm{C}$ for 5 minutes. Following PCR, the 180-bp product was digested by 2 units of Msp 1 restriction enzyme (New England Biolabs) with $1.2 \mu \mathrm{l}$ of $10 \times \mathrm{Msp} 1 \mathrm{buffer}$ at $37^{\circ} \mathrm{C}$ for 2 hours. The Msp 1 digested PCR fragments were separated by electrophoresis on $2 \%$ agarose gel for 3 hours.

\section{Scoring of eNOS T-786C Genotypes}

Genotypes were scored by electrophoretic bands using ultraviolet fluorography and ethidium bromide staining as follows: TT homozygotes with $140 \mathrm{bp}$ and $40 \mathrm{bp}$; CC homozygotes with $90 \mathrm{bp}, 50 \mathrm{bp}$, and $40 \mathrm{bp}$; and TC heterozygotes with $140 \mathrm{bp}, 90 \mathrm{bp}, 50 \mathrm{bp}$, and $40 \mathrm{bp}$. Genotypes were stratified according to ethnicities, preterm and full-term status, and prematurity conditions.

\section{Results}

We analyzed 124 participants with IVH and respiratory conditions of prematurity for the presence of eNOS T-786C mutation by PCR-RFLP analysis. The baseline carrier (-786TC) frequency was 0.15 in the control patients and 0.31 in the study participants, a statistically significant difference (Table 1). The mutant allele -786C was present in $19(15.3 \%)$ of 124 premature infants with RDS, $\mathrm{BPD}$, and IVH conditions compared with 9 (7.25\%) of 124 premature control patients (Table 2). Thus, there was a significant 2-fold increase in the mutant allele in the patients compared with the controls $(\mathrm{p}<0.05$, OR $>2.3$ [95\% CI 1.1-5.2]). Comparison by genotype revealed that the heterozygote mutation was found in $19(31 \%)$ of 62 participants compared with only 9 (15\%) of 62 controls, a statistically significant difference $(p=0.03)$. Both the mutated allele and heterozygote eNOS mutation are significant risk factors in the origin of respiratory and IVH conditions in premature infants.

\section{Discussion}

The discovery of NO and its vascular effects has led to numerous studies for the treatment and prevention of 
TABLE 2: Frequencies of eNOS T-786C alleles in premature infants with and without IVH and respiratory conditions

\begin{tabular}{lrrrcr}
\hline & $\begin{array}{c}\text { No. of } \\
\text { Allele } \\
\text { Patients }\end{array}$ & $\begin{array}{c}\text { Fre- } \\
\text { quen- } \\
\text { cy }\end{array}$ & $\begin{array}{c}\text { No. of } \\
\text { Controls }\end{array}$ & $\begin{array}{c}\text { Fre- } \\
\text { quency }\end{array}$ & p Value $(\mathrm{OR}, 95 \% \mathrm{Cl})$ \\
\hline$-786 \mathrm{~T}$ & 105 & 0.85 & 115 & 0.93 & \\
$-786 \mathrm{C}$ & 19 & 0.15 & 9 & 0.07 & $<0.05^{*}(>2.3,1.1-5.2)$ \\
total & 124 & 1.0 & 124 & 1.0 & \\
\hline
\end{tabular}

* $\mathrm{C}$ allele frequency in patients was significantly different from controls.

certain diseases. Nitric oxide is produced from the amino acid L-arginine by the enzymatic action of NOS. Nitric oxide synthase occurs in 3 forms: neuronal and endothelial (both constitutive), and inducible. ${ }^{10,14,17,21,24}$ Each form is synthesized on a separate gene loci located on 3 different chromosomes. There are 2 endothelial forms of NOS: constitutive NOS (cNOS) and inducible NOS (iNOS)..$^{21}$ Under basal conditions, NO is continually being produced. The stimulation for the production of NO occurs by 2 different mechanisms. First, increased blood flow produces a force that acts on the vascular endothelium, and the second step involves calcium release and subsequent eNOS activation.

Vascular actions of NO include direct and indirect vasodilatation, antithrombotic effects by inhibiting platelet adhesion to the vascular endothelium, antiinflammatory effects by inhibiting leukocyte adhesion to vascular endothelium, and antiproliferative effects by inhibiting smooth muscle hyperplasia.5,14,15,20 Thus, impaired production or reduced bioavailability of NO can result in a variety of clinical vascular manifestations. Recent literature has focused on the use of inhaled NO therapy to treat

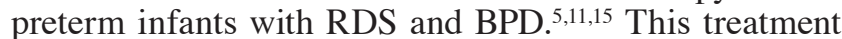
has been shown to be effective in reducing deaths and the need for extracorporeal membrane oxygenation in fullterm and near-term infants and its use is advocated for these groups of infants with hypoxic respiratory failure. In the premature infant, the results are less conclusive. However, it does appear that early, low-dose inhaled NO has a positive effect in acute oxygenation improvement. ${ }^{5,11}$ However, these benefits are still under investigation and are not yet considered standard treatment. ${ }^{5}$

Interestingly, inhaled NO does appear to have a secondary beneficial effect in neurological conditions of prematurity. Multiple studies have found that early low-dose NO inhalation therapy decreased the incidence of severe IVH, periventricular leukomalacia, and ventriculomegaly. ${ }^{1}$ Neurodevelopment outcomes have also been shown to be improved by the use of inhaled NO in preterm infants specifically, and reduced occurrences of cerebral palsy in those infants treated with inhaled NO. Therefore, eNOS and NO are critically important to both respiratory and cerebral development in the premature infant.

Our laboratory has been intensely involved in the study of genetic markers affecting prematurity such as ILs, CD14, ACE, and NOS. In earlier studies, we have shown that genetic polymorphisms in IL-6, IL-10, and
CD14 may alter the risk for blood stream infections and outcomes of sepsis in VLBW infants receiving ventilation therapy. In contrast, we have reported that the ACE insertion/deletion polymorphism does not have a significant effect on the incidence or outcome of sepsis in these VLBW infants. ${ }^{21}$ We have also demonstrated that the ACE insertion/deletion polymorphism was not associated with an increased risk of death or BPD in VLBW infants.

In examining respiratory conditions of prematurity, we have reported that the IL10G-1082A polymorphism does not have a major influence on mortality or the development of BPD in VLBW infants receiving ventilation therapy. We have also demonstrated the association of several other genetic markers in VLBW infants receiving ventilation therapy. ${ }^{21,22}$ Other genetic polymorphisms have been found at significantly higher rates in preterm infants in general compared with full-term infants. In terms of NOS, however, only iNOS was found to be statistically higher in preterm infants. The eNOS polymorphisms do not appear to be elevated in prematurity alone, but only in specific conditions of prematurity. ${ }^{8}$ Most recently, we have found a novel allele of the eNOS polymorphism in asthmatics of the Caucasian population. All of these findings give support to the possibility of genetic mutations as a risk factor for conditions of prematurity, specifically IVH and respiratory conditions.

Earlier studies have shown that thrombotic markers are risk factors in the etiology of IVH in prematurity. In the present study we examined a polymorphism located in the promoter region -786 of the eNOS gene as a potential site of alteration, leading to decreased levels of NO. The eNOS gene is located on chromosome 7q35-36, with 26 exons spanning $21 \mathrm{~kb}$, and producing 1203-1205 residues. ${ }^{16}$ Mice that are eNOS deficient have been shown to suffer severe abnormalities in lung morphogenesis, resulting in respiratory distress and death within the first few hours of life. ${ }^{9}$ The authors of that study concluded that eNOS plays a significant role in lung development and is a possible contributor to clinical syndromes of respiratory conditions of neonates.

When examining the gene of $e N O S$ at chromosome 7, the promoter region -786 has been shown to undergo a base substitution from thymine to cytosine, resulting in the mutated allele with presumed impaired NO production. The mutated $\mathrm{C}$ allele of this polymorphism has been shown in numerous studies to be associated with both coronary artery and post-subarachnoid hemorrhage vasospasm. ${ }^{4,13,16,19}$ Previous reports have also indicated that the presence of the mutant allele $-786 \mathrm{C}$ would lead to a decrease in NO levels in the cardiovascular diseases in adults, especially in coronary vasospasm. ${ }^{4} \mathrm{~A}$ recent study by Ko et al. ${ }^{12}$ revealed that polymorphism of the eNOS allele led to a statistically significant increase in risk of vasospasm after subarachnoid hemorrhage, specifically the CC genotype of the eNOS -786 polymorphism. ${ }^{2}$ We have shown that this $\mathrm{C}$ allele is also linked to an increased risk of specific conditions of prematurity.

Due to these significant intracranial vascular effects of NO, we hypothesized that the etiology of IVH must be influenced by NO production, because a genetic mutation of $e N O S$ would be a risk factor for IVH. Given earlier 


\section{P. Vannemreddy et al.}

studies in the literature, we chose to examine specifically the eNOS -786 polymorphism. Our study has shown that this mutant allele was present in a statistically significant higher percentage of patients with IVH than those without IVH. This finding suggests that this mutant allele is a significant risk factor in the origin of respiratory conditions and IVH of prematurity. These high-risk patients may benefit from low-dose NO inhalation therapy to help prevent IVH and its potentially devastating consequences.

\section{Conclusions}

Our data show that the mutant eNOS $-786 \mathrm{C}$ allele is a significant risk factor in the origin of respiratory and IVH diseases in premature infants through an insufficient supply of endogenous NO levels in these infants. Those preterm infants who exhibit the $-786 \mathrm{C}$ mutation have a 2-fold increased risk of developing respiratory disorders and IVH. Inhaled NO therapy may become a pivotal prophylactic therapy for specific high risk infants with this genetic mutation. Further studies are currently being conducted to examine the $e N O S$ gene further for additional markers that may be instrumental in the etiology of IVH alone.

\section{Disclosure}

The authors report no conflict of interest concerning the materials or methods used in this study or the findings specified in this paper.

\section{References}

1. Adams-Chapman I: Insults to the developing brain and impact on neurodevelopmental outcome. J Commun Disord 42:256-262, 2009

2. Baier RJ: Genetics of perinatal brain injury in the preterm infant. Front Biosci 11:1371-1387, 2006

3. Cherian S, Whitelaw A, Thoresen M, Love S: The pathogenesis of neonatal post-hemorrhagic hydrocephalus. Brain Pathol 14:305-311, 2004

4. Colomba D, Duro G, Corrao S, Argano C, Di Chiara T, Nuzzo D, et al: Endothelial nitric oxide synthase gene polymorphisms and cardiovascular damage in hypertensive subjects: an Italian case-control study. Immun Ageing 5:4, 2008

5. Dani C, Bertini G: Inhaled nitric oxide for the treatment of preterm infants with respiratory distress syndrome. Neonatology 94:87-95, 2008

6. Duncan C, Chiang V: Intraventricular hemorrhage and posthemorrhagic hydrocephalus, in Albright AL, Pollack IF, Adelson PD (eds): Principles and Practice of Pediatric Neurosurgery. New York: Thieme, 1999, pp 107-124

7. Duncan C, Ment L: Posthemorrhagic hydrocephalus in the premature infant, in Cheek W (ed): Pediatric Neurosurgery Surgery of the Developing Nervous System. Philadelphia: WB Saunders, 1994, pp 242-247

8. Gibson CS, MacLennan AH, Dekker GA, Goldwater PN, Dambrosia JM, Munroe DJ, et al: Genetic polymorphisms and spontaneous preterm birth. Obstet Gynecol 109:384-391, 2007

9. Han RN, Babaei S, Robb M, Lee T, Ridsdale R, Ackerley C, et al: Defective lung vascular development and fatal respiratory distress in endothelial NO synthase-deficient mice: a model of alveolar capillary dysplasia? Circ Res 94:1115-1123, 2004

10. Hingorani AD, Liang CF, Fatibene J, Lyon A, Monteith S, Par- sons A, et al: A common variant of the endothelial nitric oxide synthase (Glu298 ->Asp) is a major risk factor for coronary artery disease in the UK. Circulation 100:1515-1520, 1999

11. Kinsella JP, Cutter GR, Walsh WF, Gerstmann DR, Bose CL, Hart C, et al: Early inhaled nitric oxide therapy in premature newborns with respiratory failure. N Engl J Med 355:354364, 2006

12. Ko NU, Rajendran P, Kim H, Rutkowski M, Pawlikowska L, Kwok P, et al: Endothelial nitric oxide synthase polymorphism (-786T-C) and increased risk of angiographic vasospasm after aneurysmal subarachnoid hemorrhage. Stroke 39:1103-1108, 2008

13. Krediet T, Kavelaars A, Vreman H, Heijnene C, Van Bel F: Respiratory distress syndrome-associated inflammation is related to early but not late peri/intraventricular hemorrhage in preterm infants. J Peds 148: 740-746 2006

14. Ordóñez AJ, Carreira JM, Franco AG, Sánchez LM, Alvarez MV, García EC: Two expressive polymorphisms on the endothelial nitric oxide synthase gene (intron 4, 27 bp repeat and $-786 \mathrm{~T} / \mathrm{C}$ ) and the venous thromboembolism. Thromb Res 99:563-566, 2000

15. Su PH, Chen JY: Inhaled nitric oxide in the management of preterm infants with severe respiratory failure. J Perinatol 28:112-116, 2008

16. Tsukada T, Yokoyama K, Arai T, Takemoto F, Hara S, Yamada A, et al: Evidence of association of the ecNOS gene polymorphism with plasma NO metabolite levels in humans. Biochem Biophys Res Commun 245:190-193, 1998

17. Ursin SA, Yanamandra K, Boggs P, Napper D, Thurmon TF, Chen $\mathrm{H}$, et al: Ethnic differences in distribution of important asthma-associated polymorphisms. Genet Med 7:64, 2005

18. Vergani P, Patanè L, Doria P, Borroni C, Cappellini A, Pezzullo JC, et al: Risk factors for neonatal intraventricular haemorrhage in spontaneous prematurity at 32 weeks gestation or less. Placenta 21:402-407, 2000

19. Wang XL, Wang J: Endothelial nitric oxide synthase gene sequence variations and vascular disease. Mol Genet Metab 70:241-251, 2000

20. Yanamandra K, Boggs PB, Thurmon TF, Lewis D, Bocchini JA Jr, Dhanireddy R: Novel allele of the endothelial nitric oxide synthase gene polymorphism in Caucasian asthmatics. Biochem Biophys Res Commun 335:545-549, 2005

21. Yanamandra K, Loggins J, Baier R: The angiotensin converting enzyme insertion/deletion polymorphism is not associated with an increased risk of death or bronchopulmonary dysplasia in ventilated very low birthweight infants. BMC Pediatr 4:26-33, 2004

22. Yanamandra K, Loggins J, Baier R: Endothelial NOS polymorphisms and ROP in very low birth weight infants. PAS Rep 57:542, 2005

23. Yanamandra K, Vannemreddy P, Napper D, Pramanik A, Bocchini JA Jr, Boggs P, et al: Mutant eNOS genotypes lead to delayed cardiopulmonary transition and need for supplemental $\mathrm{O}_{2}$ therapy in premature infants. Presented at the 2009 annual meeting of the Pediatric Academic Societies (Abstract 5755.8). http://www.abstracts2view.com/pas [Accessed November 4, 2009]

24. Yoon Y, Song J, Hong SH, Kim JQ: Plasma nitric oxide concentrations and nitric oxide synthase gene polymorphisms in coronary artery disease. Clin Chem 46:1626-1630, 2000

Manuscript submitted June 14, 2009.

Accepted October 9, 2009.

Address correspondence to: Prasad Vannemreddy, M.D., Department of Neurosurgery, LSUHC-Shreveport, Louisiana 71103. email: prasad4458@hotmail.com. 